\title{
Ranking and Evaluating CT Departments by Fuzzy Logic
}

\author{
Mohammed Shrief \\ Helwan University \\ Biomedical Engineering Dept.
}

\author{
Walid Al-Atabany \\ Helwan University \\ Biomedical Engineering Dept.
}

\author{
Mohamed El-Wakad \\ Helwan University \\ Biomedical Engineering Dept.
}

\begin{abstract}
Rankings approaches are a public way of providing information in different fields. In health care domain, the direct impact of the ranking systems is that these hospitals will explore all the paths to improve their rank that reflect on attracting more patients. Current methodologies mainly include subjective indicators in their ranking systems. The purpose of this paper is to develop a new quantitative ranking model based on multi-criteria decision making using fuzzy logic to rank the computed tomography (CT) departments in hospitals. The system is based on factors extracted from both the hospitals and the CT scan devices. The output of the system from 30 different hospitals has been compared with experts' opinions showing an average error of $2.17 \pm 1.8$.
\end{abstract}

\section{Keywords}

Rranking,computed tomography(CT),fuzzy logic control

\section{INTRODUCTION}

Nowadays, rankings have become very important way to synthesize and offer information about a range of selections to customers and give them best information to select the best for them.. Generally, consumers tend to depend on each other for advice for everything from schools,restaurants and hotels to lawyers and professors.Academic research has proved that, ranking scan have a great effect on consumer decision. In the United Kingdom three national rankings of universities are published annually by The Complete University Guide based on a number of criteria such as student satisfaction and quality of research[1].In the health care sector, United States and world news (U.S. News \& World Report), evaluates more than 5,000 specialized medical centers across the United States.

Most of the hospitals ranking sites depend on the opinion of patients and doctors based on criteria such as medical quality and outcomes, value for safety, patient safety and security, website and management. This method is very common but not accurate.In [2], Axial Exchange and Becker's Hospital Review ranked 3,077 U.S hospitals' based on statistical analysis collected from patient engagment data. They used four main criteria ;Readmissions (25\%), Patient satisfaction (25\%), Patient education and self care tools (25\%) and Social media engagement (25\%). In [3], GoLocal conducted a survey through asking a random sample of patients to give feedback about topics involving how well nurses and doctors communicated, how responsive hospital staff were to patient needs, how well the hospital controlled patients' pain, and the cleanliness and quietness of the hospital environment.

In [4], the Medical Travel Quality Alliance (MTQUA) provides international hospital ranking for tourists through an extensive review of each hospital's programs and protocols affecting medical tourists including the quality and effectiveness of their international and internal patient communication, marketing, website and social media activities; their external partnerships and alliances; internal care management protocols; and attention to patient safety, security and privacy.

From the previous literature, It is clear that most of the ranking strategies was only based on the public engagment evaluation, ignoring any mathematical modeling that can rely on measurable quantitative parameters. Also in developing countries, the concept of specialized hospitals is rare, so there is a need to build a system that evaluate and rank the hospitals based on the departments categories. The objective of this paper isto design a mathematical system for ranking and evaluating the CT departments in hospitals based on qualitative as well as quantitative measurements from both the hospital and department itself. These measurements are grouped into four main criterias which inherently include sub criterias as shown in Fig 1.The impact from this system should help in improving and developing the medical technology in developing countries.

Generally most ranking approaches follow a logical set of elements. First, data are collected, either from existing sources or from original surveys. Following this, the type and quantity of variablesare selected from the gathered information. Next, the indicators are standardized and weightedfrom the selected variables. Finally, model calculations are conducted and comparisons made so thatinstitutions are sorted into "ranked order".

Ranking systems can be carried out by applying multi-criteria decision making approaches, such as analytic hierarchy process (AHP), quality function deployment(QFD) and Fuzzy logic [5-8]. In this paper we use the Fuzzy logic to build our ranking model and we verify its output with relevant expertise. Fuzzy concepts have been widely used in the field of ranking and supplier selection issues [9-13]. However, the use of it in the healthcare ranking is very rare. In our proposed model, the criteria and sub-criteria are quantitative values such as power stability, device performance,dimensions and air condition and safety.

The paper is organized as follows: First, an explanation of the methodology of the model including its equations, membership functions, equations and flowchart of it. Second, the results and discussions of the model showing the differences in results between the experts and model. Third, the conclusions of this paper

\section{METHODOLOGY}

Lotfi A. Zadeh initiated fuzzy set theory to simulate the human thinking in decision making by using linguistic terms and degrees of membership. A fuzzy set is a category of objects with grades of normalized membership function between zero and one[14]. These grades present the degree of fixity with which specific item belongs to a fuzzy set. 


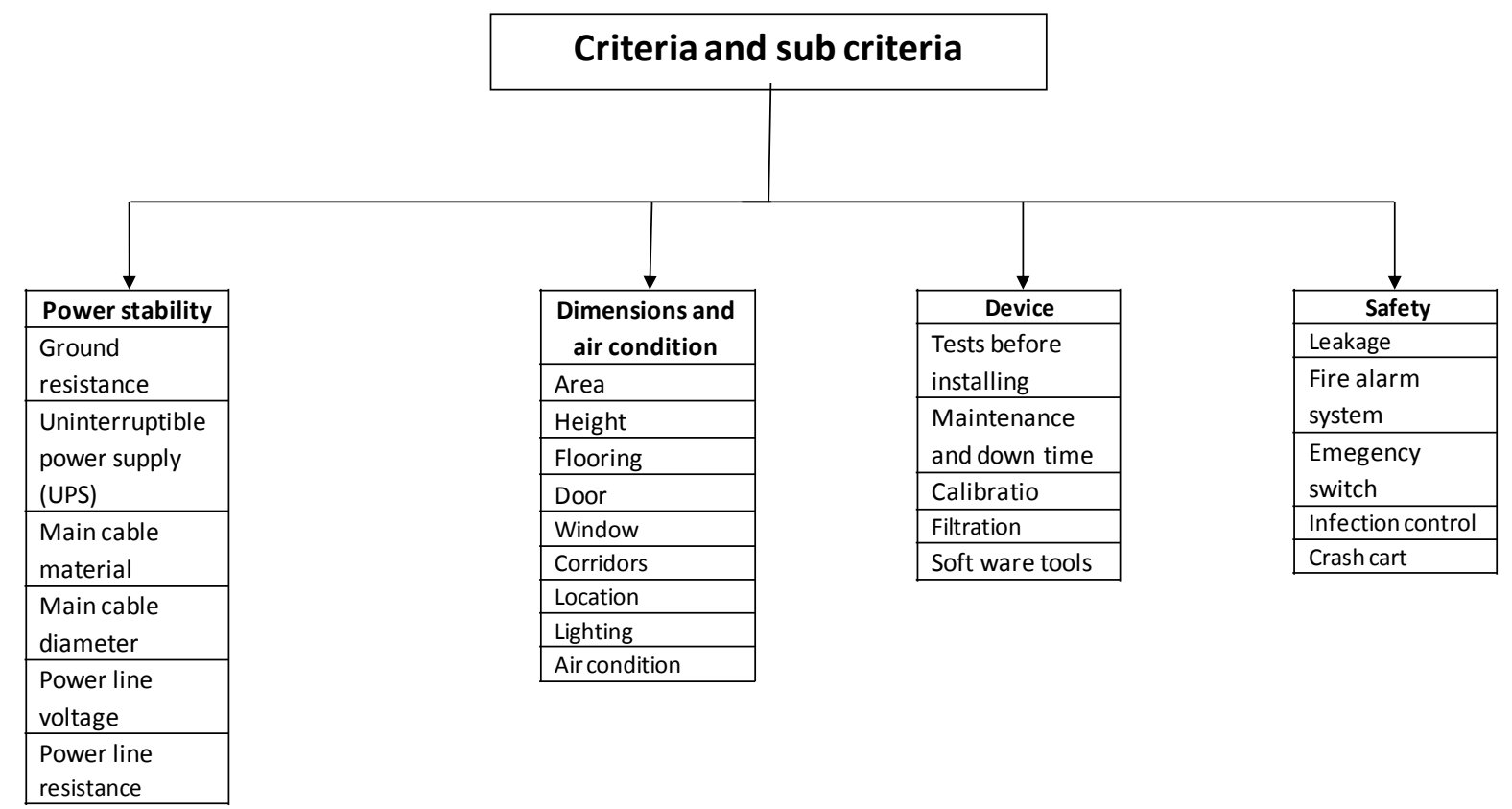

Fig 1. The criteria and sub criteria of the model.

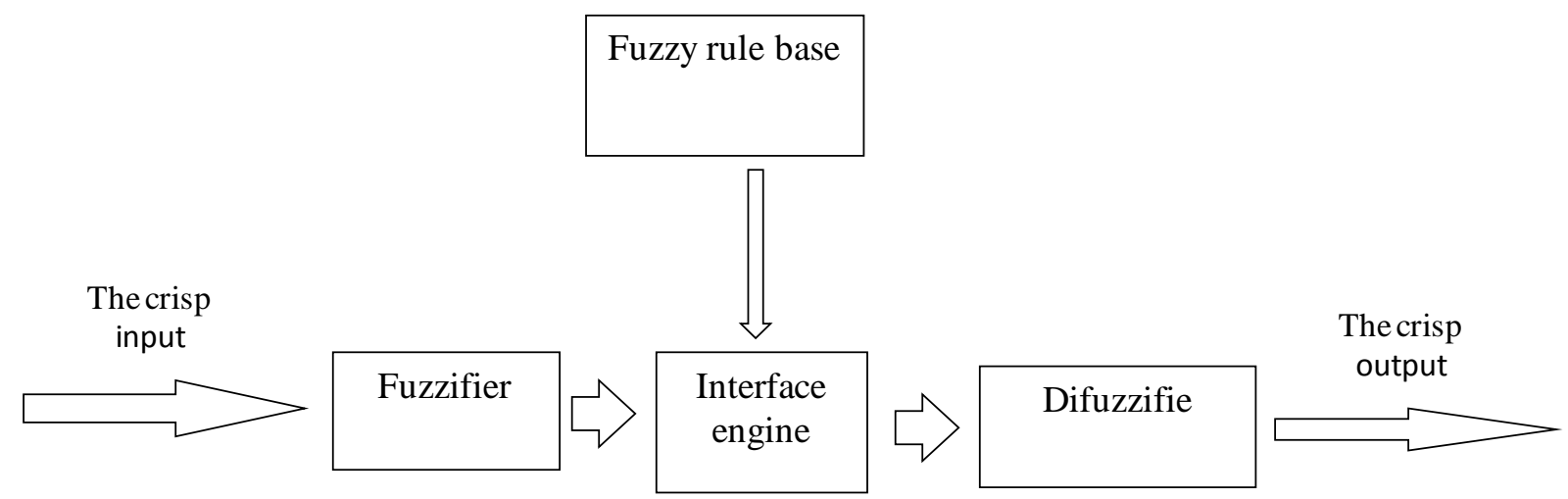

Fig 2. The Mamdani's fuzzy inference system.

Mamdani in 1974, concluded the feasibility of using synthetic base of inference[15]. The Mamdani FIS system has 4 parts as shown in Fig 2.

- Fuzzifier: in this part, the inputs are represented by membership functions to transfer crisp values into fuzzy value. There are many forms for the membership functions to represent different types of fuzziness such as linear shape and exponential shape. The most common used types of the membership functions are triangular, trapezoid and gaussian membership functions[11].

- Rules: it is the main part of any FIS model. "ifthen" rules are the fundamental of experts knowledge for each area. The rule can be written as" if $z_{1}$ is $c_{1}$ and $z_{2}$ ic $d_{1}$, then $y$ is $m_{1}$ ". So that $z_{1}$ and $z_{2}$ are variables, $\mathrm{y}$ is solution variable, and $c_{1}$, $d_{1}$ and $m_{1}$ are fuzzy linguistic terms.

- Interface engine : the fuzzy interface engine defines the relation between the input fuzzy sets and output fuzzy sets.It determines the degree to which the antecedent is satisfied for each rule. It is possible that one rule or more rules can fire at the same time.

- Defuzzifier::it transforms the generated fuzzy output from the interface engine to crisp values. It is the most computational complexity part. There are many methods for difuzzication such as center of areamethod (COA), mean of maximum (MOM), bisector of area (BOA), thelargest of maximum (LOM), and smallest of maximum (SOM)[16].

\section{CONSRTUCTING THE MODEL}

We use four main parameters as inputs to the proposed fuzzy model; power stability, dimensions and air condition[17], device[18-20] and safety[21-24]. Each parameter consists from several subparameters. The weight of each parameter and sub-parameter is calculated based on the decision makers' opinion. In which 57 experts from diverse of ray technicians and radiologists and biomedical engineers specialized in CT devices has been asked to put 
Table 1. weights of the parameters

\begin{tabular}{|c|c|c|}
\hline The measurement grades & value & Weight of sub-criteria \\
\hline $\mathbf{R}_{\mathbf{G}}:$ It is the measurement grade of ground resistance in the department. & 0.205 & $\mathrm{w}_{\mathrm{g}}$ (weight of ground resistance). \\
\hline $\mathbf{U P S}_{\mathbf{G}}$ : It is the measurement grade of UPS in the department. & 0.223 & $\begin{array}{l}\mathrm{w}_{\text {ups }} \text { (weight of uninterruptible power supply } \\
\text { (UPS). }\end{array}$ \\
\hline $\mathbf{C M}_{\mathbf{G}}:$ It is the measurement grade of main cable material in the department. & 0.123 & $\mathrm{w}_{\mathrm{cm}}$ (weight of main cable material). \\
\hline $\mathbf{C D}_{\mathbf{G}}:$ It is the measurement grade of main cable diameter in the department. & 0.097 & $\mathrm{w}_{\mathrm{cd}}($ weight of main cable diameter). \\
\hline $\mathbf{P L V}_{\mathbf{G}}$ : It is the measurement grade of power line voltage in the department. & 0.191 & $\mathrm{w}_{\mathrm{plv}}($ weight of power line voltage). \\
\hline $\mathbf{P L R}_{\mathbf{G}}$ : It is the measurement grade of power line resistance in the department. & 0.151 & $\mathrm{w}_{\mathrm{plr}}$ (weight of power line resistance) \\
\hline $\mathbf{A}_{\mathbf{G}}$ : It is the measurement grade of area in the department. & 0.123 & $\mathrm{w}_{\mathrm{a}}$ (weight of area) \\
\hline $\mathbf{H}_{\mathbf{G}}$ : It is the measurement grade of height in the department. & 0.077 & $\mathrm{w}_{\mathrm{h}}($ weight of height $)$ \\
\hline $\mathbf{F}_{\mathbf{G}}$ : It is the measurement grade of flooring in the department. & 0.087 & $\mathrm{w}_{\mathrm{f}}$ (weight of flooring) \\
\hline $\mathbf{D}_{\mathbf{G}}$ : It is the measurement grade of door in the department. & 0.094 & $\mathrm{w}_{\mathrm{d}}($ weight of door $)$ \\
\hline $\mathbf{W}_{\mathbf{G}}$ : It is the measurement grade of window in the department. & 0.079 & $\mathrm{w}_{\mathrm{w}}$ (weight of window) \\
\hline $\mathbf{C R}_{\mathbf{G}}$ : It is the measurement grade of corridors in the department. & 0.077 & $\mathrm{w}_{\mathrm{c}}$ (weight of corridors) \\
\hline $\mathbf{L C}_{\mathbf{G}}$ : It is the measurement grade of location in the department. & 0.092 & $\mathrm{w}_{\mathrm{lc}}($ weight of location) \\
\hline $\mathbf{L}_{\mathbf{G G}}$ : It is the measurement grade of lighting in the department. & 0.075 & $\mathrm{w}_{\mathrm{lg}}$ (weight of lighting) \\
\hline $\mathbf{A C}_{\mathbf{G}}$ : It is the measurement grade of air conditioner in the department. & 0.297 & $\mathrm{w}_{\mathrm{ac}}$ (weight of air conditioner ) \\
\hline $\mathbf{T}_{\mathbf{G}}$ : It is the measurement grade of tests before installing in the department. & 0.186 & $\mathrm{w}_{\mathrm{t}}$ (weight of tests before installing) \\
\hline $\begin{array}{l}\mathbf{M}_{\mathbf{G}}: \text { It is the measurement grade of maintenance and down time in the } \\
\text { department. }\end{array}$ & 0.253 & $\mathrm{w}_{\mathrm{m}}$ (weight of maintenance and down time) \\
\hline $\mathbf{C B}_{\mathbf{G}}:$ It is the measurement grade of calibration in the department. & 0.180 & $\mathrm{w}_{\mathrm{cb}}$ (weight of calibration) \\
\hline $\mathbf{F}_{\mathbf{G}}$ : It is the measurement grade of filtration in the department. & 0.174 & $\mathrm{w}_{\mathrm{f}}$ (weight of filtration) \\
\hline $\mathbf{S F}_{\mathbf{G}}:$ It is the measurement grade of soft ware tools in the department. & 0.224 & $\mathrm{w}_{\mathrm{sf}}$ (weight of soft ware tools) \\
\hline $\mathbf{L}_{\mathbf{G}}:$ It is the measurement grade of leakage in the department. & 0.283 & $\mathrm{w}_{\mathrm{l}}($ weight of leakage) \\
\hline $\mathbf{F A S}_{\mathbf{G}}$ : It is the measurement grade of fire alarm system in the department. & 0.180 & $\mathrm{w}_{\text {fas }}($ weight of fire alarm system) \\
\hline $\mathbf{E S}_{\mathbf{G}}$ : It is the measurement grade of emegency switch in the department. & 0.205 & $\mathrm{w}_{\mathrm{es}}$ (weight of emegency switch) \\
\hline $\mathbf{I C}_{\mathbf{G}}$ : It is the measurement grade of infection control in the department. & 0.181 & $\mathrm{w}_{\mathrm{ic}}($ weight of infection control) \\
\hline $\mathbf{C C}_{\mathbf{G}}$ : It is the measurement grade of crash cart in the department. & 0.153 & $\mathrm{w}_{\mathrm{cc}}$ (weight of crash cart) \\
\hline
\end{tabular}

weight value for each parameter and sub parameter. Table 1 shows the average weights for these sub-parameters. Then the four parameters' values have been calculated from the following equations

For power stability:

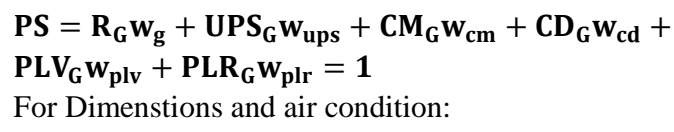



For device:

$$
\begin{aligned}
& \mathrm{D}=\mathrm{T}_{\mathrm{G}} \mathrm{w}_{\mathrm{t}}+\mathrm{M}_{\mathrm{G}} \mathrm{w}_{m}+\mathrm{CB}_{\mathrm{G}} \mathrm{w}_{\mathrm{cb}}+\mathrm{F}_{\mathrm{G}} \mathrm{w}_{\mathrm{f}}+\mathrm{SF}_{\mathrm{G}} \mathrm{w}_{\mathrm{sf}}=\mathbf{1} \\
& \text { For safety: } \\
& S=\mathrm{L}_{\mathrm{G}} \mathrm{w}_{\mathrm{l}}+\mathrm{FAS}_{\mathrm{G}} \mathrm{w}_{\mathrm{fas}}+\mathrm{ES}_{\mathrm{G}} \mathrm{w}_{\mathrm{es}}+\mathrm{IC}_{\mathrm{G}} \mathrm{w}_{\mathrm{ic}}+\mathrm{CC}_{\mathrm{G}} \mathrm{w}_{\mathrm{cc}}=\mathbf{1}
\end{aligned}
$$

The proposed model is mainly cnstructed from two stages; in the in first stage, we take the results of the previous equations 
as inputs for power stability, dimensions and air conditioner, device and safety as crisp values. The values of these parameters are scaled between 0 and 1 . The crisp values of the four parameters are converted into three fuzzy values; low, medium and high through the membership functions.

The inputs of the second stage (the outputs of first stage) are used to fire the rules of the FIS.

Table 2. .The linguistic terms in stage 1 for ranking CT departments

$\begin{array}{ll}\text { Low } & (0.0637,0.15) \\ \text { Medium } & (0.08493,0.5) \\ \text { High } & (0.0637,0.85)\end{array}$

Table 3. The linguistic terms in stage 1 for ranking CT departments

$\begin{array}{cc}\text { Low } & (0,0.15,0.3) \\ \text { Medium } & (0.2,0.5,0.8) \\ \text { High } & (0.7,0.85,1)\end{array}$

\section{MEMBERSHIP FUNCTIONS OF THE MODEL}

In this work, after several attempts and practising, we chose two membership functions that can convey the model output with the experts openions; gaussian and triangular membership functions. A gaussian fuzzy equation is:

$\mathrm{F}(\mathrm{x})=\frac{1}{\sigma \sqrt{2 \pi}} \mathrm{e}^{-\frac{1}{2}\left(\frac{\mathrm{x}-\mathrm{c}}{\sigma}\right)^{2}}$

Where $\sigma$ is the standard deviation, $\mathrm{c}$ is the center. And triangular fuzzy equation is specified by three parametersas follows:

$\mathrm{F}(\mathrm{x})=\left\{\begin{array}{cr}0, & x \leq a . \\ \frac{x-a}{b-a}, & a \leq x \leq b . \\ \frac{c-x}{c-b}, & b \leq x \leq c . \\ 0, & x \geq c .\end{array}\right.$
We use four fuzzy sets of gaussian membership functions for four inputs to the FIS system in the first stage; power stability, dimensions and air condition, device and safety. The linguistic rating variables for these fuzzy sets are " low", "medium" and "high "as shown in Fig 3.

The equations forthelow, medium and high membership functions respectively are:

$$
\begin{aligned}
& F(x)=\frac{1}{0.0637 \sqrt{2 \pi}} \mathrm{e}^{-\frac{1}{2}\left(\frac{x-.015}{0.0637}\right)^{2}} \\
& F(x)=\frac{1}{0.08493 \sqrt{2 \pi}} \mathrm{e}^{-\frac{1}{2}\left(\frac{x-0.5}{0.08493}\right)^{2}} \\
& F(x)=\frac{1}{0.0637 \sqrt{2 \pi}} \mathrm{e}^{-\frac{1}{2}\left(\frac{x-.085}{0.0637}\right)^{2}}
\end{aligned}
$$

The numeric scale values for these variables are $0-1$ as presented in Table 2

For the output stage we use the triangular membership function with linguistic rating fuzzy set varibles include" low", "medium" and "high "as shown in Fig 4. Having numeric scale values presented in

Table 3 .

The equations for the low , medium and high membership functions respectively are:

$$
\begin{gathered}
\mathrm{F}(\mathrm{x})=\left\{\begin{array}{cc}
0, & x \leq 0 . \\
\frac{x-0}{0.15-0}, & 0 \leq x \leq 0.15 . \\
\frac{0.3-x}{0.3-0.15}, & 0.15 \leq x \leq 0.3 . \\
0, & x \geq 0.3 .
\end{array}\right. \\
\mathrm{F}(\mathrm{x})=\left\{\begin{array}{cc}
0, & x \leq 0.2 . \\
\frac{x-0.2}{0.5-0.2}, & 0.2 \leq x \leq 0.5 . \\
\frac{0.8-x}{0.8-0.5}, & 0.5 \leq x \leq 0.8 . \\
0, & x \geq 0.8 .
\end{array}\right.
\end{gathered}
$$

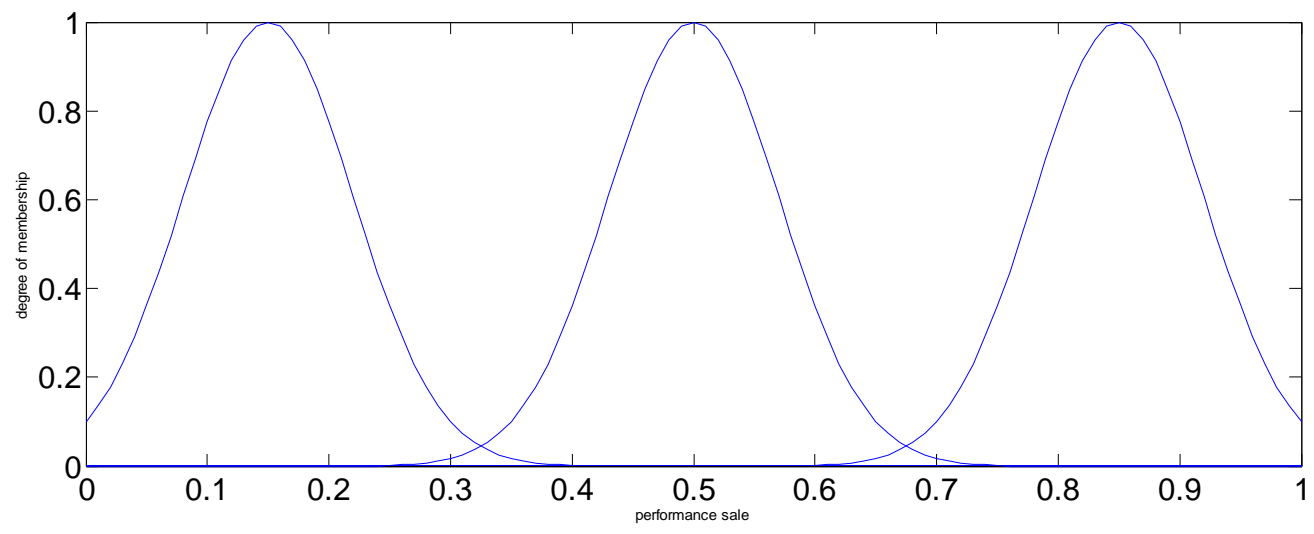

Fig 3.The membership functions in stage 1 for power stability, dimensions and air condition, device and safety. 


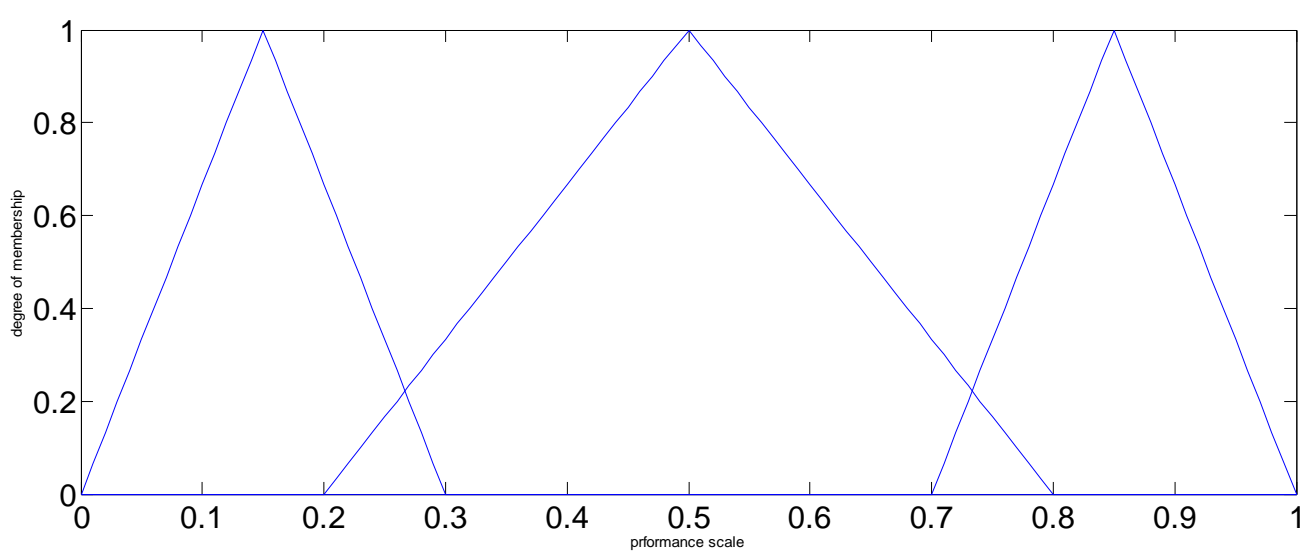

Fig 4.The membership functions in stage 2 for output

Table 4. Rules of the propsed modeling

\begin{tabular}{|c|c|c|c|c|c|c|c|c|c|c|c|c|c|}
\hline & \multicolumn{3}{|c|}{ Safety } & \multicolumn{3}{|c|}{ Device } & \multicolumn{3}{|c|}{ Power stability } & \multicolumn{3}{|c|}{$\begin{array}{c}\text { Dimensions \& air } \\
\text { condition }\end{array}$} & \multirow[t]{2}{*}{ output } \\
\hline Rules & low & med & high & Low & med & high & low & med & high & low & med & high & \\
\hline Rule1 & $*$ & & & & & & & & & & & & Low \\
\hline Rule2 & & $*$ & & $*$ & & & $*$ & & & & & & Low \\
\hline Rule3 & & $*$ & & $*$ & & & & & & $*$ & & & Low \\
\hline Rule4 & & $*$ & & & & & * & & & * & & & Low \\
\hline Rule5 & & & $*$ & $*$ & & & $*$ & & & $*$ & & & Low \\
\hline Rule6 & & $*$ & & & $*$ & & & $*$ & & & & & Medium \\
\hline Rule7 & & $*$ & & $*$ & & & & * & & & & & Medium \\
\hline Rule8 & & $*$ & & & $*$ & & & & & & $*$ & & Medium \\
\hline Rule9 & & $*$ & & & $*$ & & & & & $*$ & & & Medium \\
\hline Rule10 & & $*$ & & & & & & $*$ & & & $*$ & & Medium \\
\hline Rule11 & & $*$ & & & $*$ & & & $*$ & & & $*$ & & Medium \\
\hline Rule12 & & & $*$ & & & $*$ & $*$ & & & & & & Medium \\
\hline Rule13 & & & $*$ & $*$ & & & & & $*$ & & & & Medium \\
\hline Rule14 & & & $*$ & & & $*$ & & & & $*$ & & & Medium \\
\hline Rule15 & & & $*$ & $*$ & & & & & & & & * & Medium \\
\hline Rule16 & & & * & & & & & & $*$ & $*$ & & & Medium \\
\hline Rule17 & & & $*$ & & & & $*$ & & & & & $*$ & Medium \\
\hline Rule18 & & & $*$ & & & $*$ & & $*$ & & & $*$ & & Medium \\
\hline Rule19 & & & $*$ & & $*$ & & & & $*$ & & $*$ & & Medium \\
\hline Rule20 & & & $*$ & & $*$ & & & $*$ & & & & $*$ & Medium \\
\hline Rule21 & & $*$ & & & & $*$ & & $*$ & & & $*$ & & Medium \\
\hline
\end{tabular}




\begin{tabular}{|l|l|l|l|l|l|l|l|l|l|l|l|l|l|}
\hline Rule22 & & $*$ & & & $*$ & & & & $*$ & & $*$ & & Medium \\
\hline Rule23 & & $*$ & & & $*$ & & & $*$ & & & & $*$ & Medium \\
\hline Rule24 & & & $*$ & $*$ & & & $*$ & & & & & $*$ & Medium \\
\hline Rule25 & & & $*$ & $*$ & & & & & $*$ & $*$ & & & Medium \\
\hline Rule26 & & & $*$ & & & $*$ & $*$ & & & $*$ & & & High \\
\hline Rule27 & & & $*$ & & & $*$ & & & $*$ & & & & High \\
\hline Rule28 & & & $*$ & & & $*$ & & & $*$ & & & $*$ & High \\
\hline Rule29 & & & $*$ & & & $*$ & & & $*$ & & $*$ & & High \\
\hline Rule30 & & & $*$ & & & $*$ & & $*$ & & & & $*$ & High \\
\hline Rule31 & & & $*$ & & $*$ & & & & $*$ & & & $*$ & High \\
\hline Rule32 & & $*$ & & & & $*$ & & & $*$ & & & $*$ & High \\
\hline Rule33 & & & $*$ & & & $*$ & & & $*$ & $*$ & & & High \\
\hline Rule34 & & & $*$ & & & $*$ & $*$ & & & & & $*$ & High \\
\hline Rule35 & & $*$ & $*$ & & & & & $*$ & & & $*$ & High \\
\hline
\end{tabular}

$\mathrm{F}(\mathrm{x})=\left\{\begin{array}{cc}0, & x \leq 0.7 \\ \frac{x-0.7}{0.85-0.7}, & 0.7 \leq x \leq 0.85 . \\ \frac{1-x}{1-0.85}, & 0.85 \leq x \leq 1 . \\ 0, & x \geq 1 .\end{array}\right.$

\section{GENERATING THE RULES}

The linguistic rules of the fuzzy system have been generatedto convey with expert knowledge.Safety parameter takes the highest priority when putting the rules so the first rule is " if safety is low the output is low" . The total number of rules that used in our model equals 35 rules as listed in Table 4.

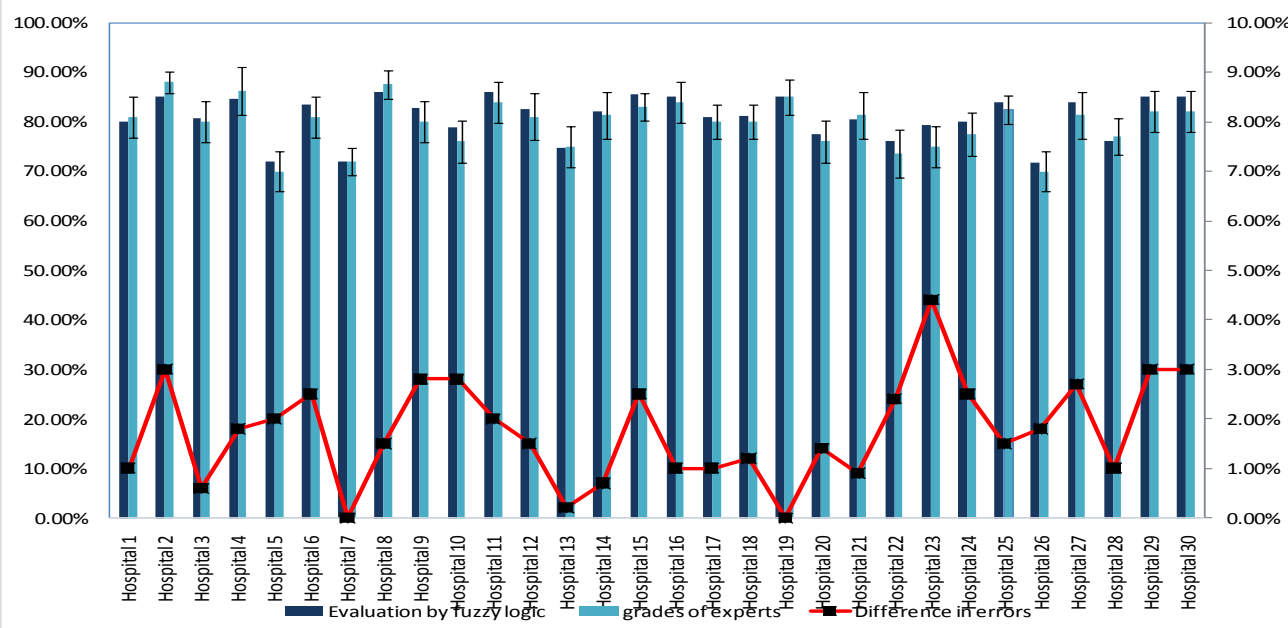

Fig 5. Model assessment by experts grades for $30 \mathrm{CT}$ departments and the percentage of error between them.

\section{DEFUZZIFICATION OF THE FUZZYOUT OUTPUT}

Deifuzzification process involves converting the output values from fuzzy value to crisp value. There are different techniques to do the defuzzification step. In this paper; we use Center of Area (COA) approach which is considered to be the most common methods for defuzzification[25].

$$
\mathrm{COA}=\frac{\int_{X_{\min }}^{X_{\max }} f(x) \cdot x d x}{\int_{X_{\min }}^{X_{\max }} f(x) \cdot x d x}
$$

Where CoA is the center of area, $x$ is the value of the linguistic variable, and $x \min$ and $x \max$ represent the range of the linguistic variable. 


\section{RESULTS AND DISSCUSION}

We have applied the proposed model in 30 CT departments at different hospitals in Egypt. To validate the output of our fuzzy system, we compared it with the experts evaluation for these department as shown in Fig 5. 150 experts were participated in the evaluation process, in average 5 for each hospitals. 30 out of these participants have been chosen to be doctors with an average of $8 \pm 1.287$ years of experience in the radiology field , 60 to be clinical engineers working in the radiology field with and average experience of $13 \pm 2$ years and 60 to be CT scan technician working in the radiology field with and average experience of $18 \pm 2$ years.

As shown from the results, the average error of the difference between our system output and the experts ranking is 2.17 \pm 1.8 with maximum error of $4.4 \%$. The reason for this peak error in hospital No. 23 is that experts assigned less value for the safety criterion than the value set by the fuzzy model. This small error differences verifies the reliability of our proposed model and approves the generated rules of the system which convey with opinions and suggestions of experts.

Also we can see that the standard deviation of the averaged experts' decisions did not exceed $5 \%$ which indicates the seriousness and quality of experts involved in the evaluation.

\section{CONCLUSIONS}

We showed in this paper a fuzzy model for ranking the CT departments in non-specialized hospitals. Constructing the model was based on quantitative measurements and not on opinion polls patients. Results showed that the factors related to power stability, dimensions and air condition, device and safety are considered to be major parameters for ranking CT departments. The impact from this model will assist the patients to select the best CT department in hospitals. Also the model can be adapted to rank other departments and scaled to include the whole hospital.

\section{REFERENCES}

[1] C. Giannoulis and A. Ishizaka, "A Web-based decision support system with ELECTRE III for a personalised ranking of British universities," Decision Support Systems, vol. 48, pp. 488-497, 2010.

[2] D. J. Skiba, "The Connected Age: Digital Tools for Health," Nursing Education Perspectives, vol. 35, pp. 415-417, 2014.

[3] R. J. Zall, B. J. Kinsella, and L. Proskauer Rose, "Going Private: Navigating State Review of Nonprofit Hospital Conversions."

[4] K. M. Wong, P. Velasamy, and T. N. T. Arshad, "Medical Tourism Destination SWOT Analysis: A Case Study of Malaysia, Thailand, Singapore and India," in SHS Web of Conferences, 2014, p. 01037.

[5] C. Kahraman, T. Ertay, and G. Büyüközkan, "A fuzzy optimization model for QFD planning process using analytic network approach," European Journal of Operational Research, vol. 171, pp. 390-411, 2006.

[6] O. S. Vaidya and S. Kumar, "Analytic hierarchy process: An overview of applications," European Journal of operational research, vol. 169, pp. 1-29, 2006.
[7] L. Vanegas and A. Labib, "A fuzzy quality function deployment (FQFD) model for deriving optimum targets," International Journal of Production Research, vol. 39, pp. 99-120, 2001.

[8] L.-K. Chan and M.-L. Wu, "Quality function deployment: A literature review," European Journal of Operational Research, vol. 143, pp. 463-497, 2002.

[9] A. Awasthi, S. S. Chauhan, and S. Goyal, "A fuzzy multicriteria approach for evaluating environmental performance of suppliers," International Journal of Production Economics, vol. 126, pp. 370-378, 2010.

[10] E. Bottani and A. Rizzi, "An adapted multi-criteria approach to suppliers and products selection-An application oriented to lead-time reduction," International Journal of Production Economics, vol. 111, pp. 763-781, 2008.

[11] C.-M. Chen, "A fuzzy-based decision-support model for rebuy procurement," International Journal of Production Economics, vol. 122, pp. 714-724, 2009.

[12] H. S. Woo and S. Saghiri, "Order assignment considering buyer, third-party logistics provider, and suppliers," International Journal of Production Economics, vol. 130, pp. 144-152, 2011.

[13] S. H. Amin, J. Razmi, and G. Zhang, "Supplier selection and order allocation based on fuzzy SWOT analysis and fuzzy linear programming," Expert Systems with Applications, vol. 38, pp. 334342, 2011.

[14] L. A. Zadeh, "Fuzzy sets," Information and control, vol. 8, pp. 338-353, 1965.

[15] E. H. Mamdani, "Application of fuzzy algorithms for control of simple dynamic plant," in Proceedings of the Institution of Electrical Engineers, 1974, pp. 1585-1588.

[16] D. Moazami, H. Behbahani, and R. Muniandy, "Pavement rehabilitation and maintenance prioritization of urban roads using fuzzy logic," Expert Systems with Applications, vol. 38, pp. 12869-12879, 2011.

[17] D. Salem and M. A.-R. M. S. Specifications, "For Basic Diagnostic Radiology Departments, qulity radiology services for better health," Egypt-Swiss Radiology Project (ESRP), pp. 1-47, 2011.

[18] K. Kiekens, F. Welkenhuyzen, Y. Tan, P. Bleys, A. Voet, J. Kruth, and W. Dewulf, "A test object with parallel grooves for calibration and accuracy assessment of industrial computed tomography (CT) metrology," Measurement Science and Technology, vol. 22, p. 115502, 2011

[19] K. Hashimoto, Y. Arai, K. Iwai, M. Araki, S. Kawashima, and M. Terakado, "A comparison of a new limited cone beam computed tomography machine for dental use with a multidetector row helical CT machine," Oral Surgery, Oral Medicine, Oral Pathology, Oral Radiology, and Endodontology, vol. 95, pp. 371-377, 2003. 
[20] C. J. Walsh, N. C. Hanumara, A. H. Slocum, J.-A. Shepard, and R. Gupta, "A patient-mounted, telerobotic tool for CT-guided percutaneous interventions," Journal of Medical Devices, vol. 2, p. 011007, 2008.

[21] E. D. Hotte, "Radiological Safety for Particle Accelerators: What Part Will the States Play?," Nuclear Science, IEEE Transactions on, vol. 28, pp. 1610-1613, 1981.

[22] R. Redfern, C. P. Langlotz, S. Abbuhl, M. Polansky, S. C. Horii, and H. Kundel, "The effect of PACS on the time required for technologists to produce radiographic images in the emergency department radiology suite," Journal of Digital Imaging, vol. 15, pp. 153-160, 2002.

[23] E. A. Bolyard, O. C. Tablan, W. W. Williams, M. L. Pearson, C. N. Shapiro, and S. D. Deitchman, "Guideline for infection control in healthcare personnel, 1998," Infection Control, vol. 19, pp. 407-463, 1998.

[24] R. J. Welch, A. Kolvites, and R. M. White, "Medical emergency crash cart," ed: Google Patents, 1988.

[25] W. Van Leekwijck and E. E. Kerre, "Defuzzification: criteria and classification," Fuzzy sets and systems, vol. 108, pp. 159-178, 1999. 